\title{
Factors associated with progression to macroalbuminuria in microalbuminuric Type 1 diabetic patients: the EURODIAB Prospective Complications Study
}

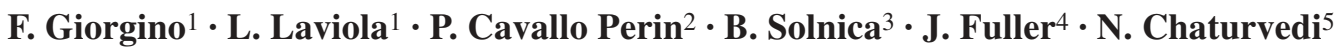 \\ ${ }^{1}$ Department of Emergency and Organ Transplantation-Section on Internal Medicine, Endocrinology and Metabolic Diseases, \\ University of Bari School of Medicine, Bari, Italy \\ 2 Department of Internal Medicine, University of Turin, Italy \\ ${ }^{3}$ Department of Clinical Biochemistry, Collegium Medicum Jagiellonian University, Krakow, Poland \\ ${ }^{4}$ EURODIAB, University College London, UK \\ ${ }^{5}$ Faculty of Medicine, Imperial College London, UK
}

\begin{abstract}
Aims/hypothesis. Type 1 diabetic patients who develop microalbuminuria are clearly disadvantaged in terms of their risk of morbidity and mortality from renal and cardiovascular diseases. It is therefore important to identify potential factors that can predict progression to macroalbuminuria.

Methods. This is a 7-year follow-up study of $352 \mathrm{mi}-$ croalbuminuric Type 1 diabetic patients from 31 European centres. Risk factors at baseline were compared in patients who progressed to macroalbuminuria and in patients who remained microalbuminuric or reverted to normoalbuminuria. Risk factors and albumin excretion rate (AER) were measured centrally.

Results. Over 7.3 years, $13.9 \%$ of the microalbuminuric patients progressed to macroalbuminuria, $35.5 \%$ remained microalbuminuric and $50.6 \%$ reverted to normoalbuminuria. Independent baseline risk factors for progression to macroalbuminuria were $\mathrm{HbA}_{1} \mathrm{c}$ (7.9\% vs $6.8 \%, p=0.004)$, AER (64.4 vs $44.9 \mu \mathrm{g} / \mathrm{min}$,
\end{abstract}

$p=0.0001)$ and-after adjusting for diabetes duration, $\mathrm{HbA}_{1} \mathrm{c}$ and AER — body weight (72 vs $67 \mathrm{~kg}, p=0.05$ ). Independent factors associated with regression to normoalbuminuria were diabetes duration (15 vs 18 years, $p=0.004)$, AER (37.2 vs $44.9 \mu \mathrm{g} / \mathrm{min}, p=0.0001$ ) andafter adjusting for diabetes duration, $\mathrm{HbA}_{1} \mathrm{c}$ and AER - waist-to-hip ratio (0.83 vs $0.86, p=0.05)$ and incidence of peripheral neuropathy at baseline $(24 \%$ vs $38 \%, p=0.001$ ). Blood pressure and smoking did not emerge as risk factors at baseline for the outcome of microalbuminuria.

Conclusions/interpretation. A significant fraction of microalbuminuric Type 1 diabetic patients will progress to overt proteinuria. Patients with higher AER values, sub-optimal metabolic control, excess body fat and peripheral neuropathy may carry a particularly high risk of clinical nephropathy requiring aggressive therapeutic intervention.

Keywords Albuminuria $\cdot$ Blood pressure $\cdot$ Metabolic control · Progression - Type 1 diabetes
Received: 3 November 2003 / Accepted: 13 February 2004 Published online: 29 May 2004

(C) Springer-Verlag 2004

F. Giorgino ( $)$

Department of Emergency and Organ Transplantation-

Section on Internal Medicine,

Endocrinology and Metabolic Diseases,

University of Bari School of Medicine,

Piazza Giulio Cesare, 11, 70124 Bari, Italy

E-mail: f.giorgino@endo.uniba.it

Tel.: +39-080-5478689, Fax: +39-080-5478689

Abbreviations: AER, albumin excretion rate .

CVD, cardiovascular disease .

Gamma GT, gamma-glutamyltransferase · OR, odds ratio ·

PCS, Prospective Complications Study · RR, relative risk ·

\section{Introduction}

Microalbuminuria in patients with Type 1 diabetes will continue to occur despite major improvements in glycaemic control, as not all patients will achieve the required levels. In addition, a proportion of patients will develop microalbuminuria irrespective of glycaemic levels. Patients who develop microalbuminuria are clearly disadvantaged in terms of their risk of morbidity and mortality, which occur from both renal and

SERR, standardised estimates of relative risk .

SREs, standardised regression effects · vWF, von Willebrand Factor 
cardiovascular diseases. Therefore, it is still important to explore risk factors associated with progression to macroalbuminuria, in order to identify novel predictive or protective factors with possible therapeutic applications. In addition, all Type 1 diabetic patients with microalbuminuria are currently treated with blockers of the renin-angiotensin system, which are known to reduce progression to macroalbuminuria and also increase the chances of reversal to normoalbuminuria [1]. However, it is not known whether this drug therapy should be indicated solely on the presence of microalbuminuria, or whether the presence of other factors which may affect progression or reversal of diabetic renal disease should also be considered.

The EURODIAB Prospective Complications Study (PCS) is ideally placed to address some of these questions, as it is the largest cohort study of people with Type 1 diabetes with centralised standardised measurements and with enough events to provide meaningful analysis. In this study, we selected patients who were microalbuminuric at baseline, and compared baseline risk factors between those who progressed to macroalbuminuria, those who remained microalbuminuric and those who reverted to normoalbuminuria.

\section{Subjects and methods}

Study procedure. Full methods of baseline and follow-up examinations have been published elsewhere [2, 3]. All subjects gave informed consent and the study was approved by the local ethics committees. In brief, a total of 3250 men and women with Type 1 diabetes were recruited from 31 centres in $16 \mathrm{Eu}-$ ropean countries. Subjects were aged between 15 and 60 at the baseline investigation phase (1989-1991) [2]. The diagnosis of Type 1 diabetes was a clinical one; it had to have occurred before the age of 36 with a continuous need for insulin within a year from diagnosis. Re-examination occurred on average 7.3 years (range: 6.0-8.5) after the baseline investigations.

At follow-up, complication status was again measured using the same protocol as baseline [2]. Two blood pressure measurements were taken at both visits, using the same standard random zero sphygmomanometer, and their mean value was used in all analyses. Hypertension was defined as diastolic blood pressure of $85 \mathrm{~mm} \mathrm{Hg}$ or more, systolic blood pressure of $135 \mathrm{~mm} \mathrm{Hg}$ or more, or the use of any anti-hypertensive medication. One 24-h urine collection was performed at baseline. The coefficient of reliability (1-[within-person variance of the difference between repeated measurements/between-person variance of a single measurement]) of this single collection was 0.97 [2], as determined by analysing data from hidden duplicate samples in a $10 \%$ subgroup of randomly selected patients. At follow-up patients performed two 24-h urine collections on two consecutive days to minimise variability. Samples were tested for infection by dipstick (Nephur test) and, if positive, the collections were discarded and a fresh collection advised after any infection had been treated. If the dipstick was negative, aliquots were frozen and sent to London for analysis of urinary albumin, using an immunoturbidimetric method [4] with goat anti-human albumin antisera (Sanofi Diagnostics Pasteur, Minn., USA) and human serum albumin standards (ORHA 20/21 grade HSA; Behring Diagnostics, Hoechst UK, Hounslow UK). The same laboratory was used for baseline and follow-up studies. The coefficient of variation for the follow-up specimens was $34 \%$, reflecting the known variability in this measure.

Diabetic peripheral neuropathy was diagnosed as reported previously $[2,5]$, on the basis of: (i) presence of one or more neuropathic symptoms; (ii) absence of two or more ankle or knee reflexes; and (iii) abnormal vibration perception threshold, measured by centrally calibrated biothesiometers (Biomedical, Newbury, Ohio, USA) on the right big toe and on the right medial malleolus.

Blood samples were taken, fasting if possible, for measurement of lipids. These were sent to a central laboratory and analysed by standard enzymatic methods (Boehringer Mannheim, Lewes, UK) on a Cobas-Bio centrifugal analyser (Roche, Welwyn Garden City, UK) [6, 7, 8]. LDL cholesterol was calculated according to the Friedewald formula [9]. For HDL measurements, samples with triglyceride concentrations of more than $3 \mathrm{mmol} / \mathrm{l}$ were diluted with $0.15 \mathrm{~mol} / \mathrm{l}$ sodium chloride solution before chemical precipitation. Glycated haemoglobin $\left(\mathrm{HbA}_{1} \mathrm{c}\right)$ was measured with an enzyme immunoassay using a monoclonal antibody against $\mathrm{HbA}_{1} \mathrm{c}$ (Dako, Ely, UK) [10]. The reference range for this assay is 2.9 to $4.8 \%$. A sample was sent locally for measurement of $\mathrm{HbA}_{1} \mathrm{c}$. At baseline the coagulation factors fibrinogen and von Willebrand Factor (vWF) were also measured [11].

Statistical analyses. These analyses are restricted to those patients who were microalbuminuric (defined as an albumin excretion rate [AER] between 20 and $200 \mu \mathrm{g} / \mathrm{min}$ ) at baseline. Follow-up AER values were the arithmetic means of AER values in the two follow-up urine collections. The rate of concordance of the two urine collections at follow-up was $85 \%$.

Baseline and follow-up characteristics for incidence were calculated using regression techniques for continuous variables, and proportions for categorical variables. Adjustment was then made for those variables that were statistically significant in relation to risk of progression and regression, and for $\mathrm{HbA}_{1} \mathrm{c}$ and diabetes duration, which were thought a priori to be the main risk factors.

Multivariate regression models are often used to understand the relative importance of several predictive variables for a given outcome. However, the direct comparison of the size of the beta coefficients of these explanatory variables is problematic, as, for example, a 1-year increase in age cannot be said to be equivalent to a $1 \%$ increase in $\mathrm{HbA}_{1} \mathrm{c}$. Standardised regression effects (SREs) are used to overcome this limitation. SREs are calculated for continuous variables by multiplying the beta estimate from logistic regression models by the standard deviation of that variable; in this case all log-transformed variables were not converted back. This allows the direct comparison of the degree of importance of each variable by standardising for population variance. Multivariate models were restricted to those individuals who had complete data on all included risk factors. A $p$ value of less than 0.05 was considered to be statistically significant.

\section{Results}

Of the 578 patients who were microalbuminuric at baseline and potentially available for follow-up, a valid urine collection was available for 352 (Fig. 1). In the total microalbuminuric cohort $55.7 \%$ of subjects had AER values between 20 and $40 \mu \mathrm{g} / \mathrm{min}$ $(n=196), 17.9 \%$ had AER values between 41 and 
Table 1. Comparison of baseline data for patients with and without an albumin excretion rate measurement at follow-up

Availability of AER measurement at follow-up

\begin{tabular}{lccc}
\cline { 2 - 4 } & No $(n=202)$ & Yes $(n=352)$ & $p$ value \\
\hline Age (years) & $32 \pm 11$ & $32 \pm 10$ & 0.7 \\
Diabetes duration (years) & $15 \pm 10$ & $16 \pm 10$ & 0.2 \\
HbA $\mathrm{c}(\%)$ & $7.4 \pm 2.1$ & $7.0 \pm 1.9$ & 0.01 \\
AER $(\mu \mathrm{g} / \mathrm{min})^{\mathrm{a}}$ & $44.2(26.0,72.0)$ & $196(25.6,65.2)$ & 0.6 \\
AER 20-40 $\mu \mathrm{g} / \mathrm{min}^{\mathrm{b}}$ & $112(55.5)$ & $63(17.9)$ & 0.8 \\
AER 41-60 $\mu \mathrm{g} / \mathrm{min}^{\mathrm{b}}$ & $33(16.3)$ & $93(26.4)$ & 0.8 \\
AER 61-200 $\mu \mathrm{g} / \mathrm{min}^{\mathrm{b}}$ & $57(28.2)$ & $125 \pm 17.5$ & 0.8 \\
Systolic BP $(\mathrm{mm} \mathrm{Hg})$ & $124 \pm 19.5$ & $77 \pm 11.6$ & 0.8 \\
Diastolic BP $(\mathrm{mm} \mathrm{Hg})$ & $76 \pm 11.3$ & $5.4 \pm 1.1$ & 0.2 \\
Cholesterol $(\mathrm{mmol} / \mathrm{l})$ & $5.5 \pm 1.3$ & $1.01(0.74,1.33)$ & 0.2 \\
Triglyceride $(\mathrm{mmol} / \mathrm{l})^{\mathrm{a}}$ & $1.15(0.79,1.51)$ & $0.85 \pm 0.11$ & 0.02 \\
WHR & $0.86 \pm 0.14$ & 0.3 &
\end{tabular}

Data are means \pm SD. ${ }^{a}$ Geometric mean (25th, 75 th centiles); ${ }^{b}$ Number of patients (\% of total). AER, albumin excretion rate; $\mathrm{BP}$, blood pressure

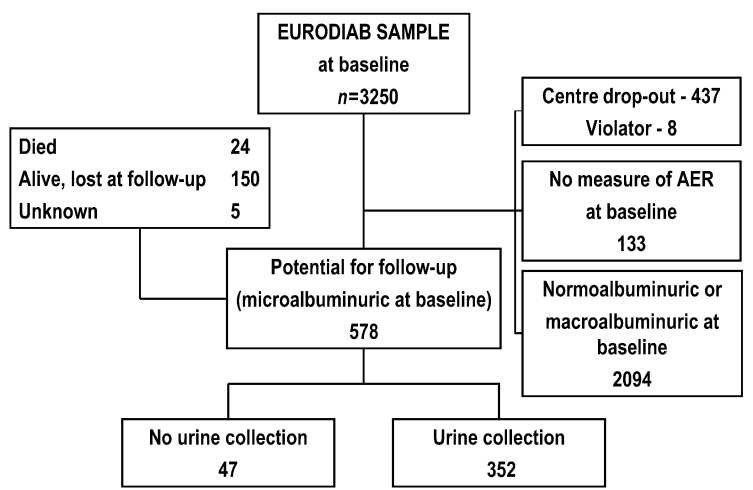

Fig. 1. Patient flow chart

$60 \mu \mathrm{g} / \mathrm{min}(n=63)$ and $26.4 \%$ had values between 61 and $200 \mu \mathrm{g} / \mathrm{min}(n=93)$ (Table 1). Data on baseline risk factors were compared both in subjects who provided and in subjects who did not provide a urine collection at follow-up, excluding those who had died (Table 1). Subjects without follow-up data had worse glycaemic control at baseline (7.4\% vs $7.0 \%, p=0.01)$. Fasting triglyceride was also worse in those not followed-up (1.15 vs $1.01 \mathrm{mmol} / \mathrm{l}, p=0.02)$. However, there was no difference in mean AER values and the distribution of AER values within the microalbuminuria range at baseline between patients with and patients without follow-up data (Table 1).

Of the 352 patients who were microalbuminuric at baseline and had valid data at follow-up, 178 reverted to normoalbuminuria $(50.6 \%), 125$ remained microalbuminuric $(35.5 \%)$ and 49 progressed to AER values greater than $200 \mu \mathrm{g} / \mathrm{min}(13.9 \%)$.

Diabetes duration was shorter in patients who reverted to normoalbuminuria (15 years) than in the other two groups (18 years, $p=0.004$ for trend) (Table 2). On the other hand, $\mathrm{HbA}_{1} \mathrm{c}$ was only significantly different at baseline in patients who progressed to macroalbuminuria $(7.9 \%$ vs $6.8 \%, p=0.004)$. Baseline AER was lowest in those who reverted to normoalbuminuria $(37.2 \mu \mathrm{g} / \mathrm{min}, p=0.0001)$ and highest in those who progressed to macroalbuminuria $(64.4 \mu \mathrm{g} / \mathrm{min}$, $p=0.0001)$. Indeed, of the patients who reverted to normoalbuminuria, $118(66.3 \%)$ had baseline AER values between 21 and $40 \mu \mathrm{g} / \mathrm{min}, 29(16.3 \%)$ had baseline values between 41 and $60 \mu \mathrm{g} / \mathrm{min}$ and $31(17.4 \%)$ had baseline values between 61 and $200 \mu \mathrm{g} / \mathrm{min}$. By contrast, in the subgroup of $49 \mathrm{pa}-$ tients with macroalbuminuria at follow-up, 14 (28.6\%) had baseline AER between 21 and $40 \mu \mathrm{g} / \mathrm{min}$, $8(16.3 \%)$ between 41 and $60 \mu \mathrm{g} / \mathrm{min}$ and $27(55.1 \%)$ between 61 and $200 \mu \mathrm{g} / \mathrm{min}$.

Fasting triglyceride and gamma-glutamyltransferase (gamma GT) were lowest in patients who reverted to normoalbuminuria and highest in those who progressed to macroalbuminuria (Table 2). In patients who progressed to macroalbuminuria vWF was also higher $(1.37 \mathrm{U} / \mathrm{ml})$ than in those who remained microalbuminuric $(1.14 \mathrm{U} / \mathrm{ml})$ or regressed to normoalbuminuria $(1.10 \mathrm{U} / \mathrm{ml})(p=0.04)$. The WHR was significantly lower in subjects who reverted to normoalbuminuria (0.83) than in the other two groups $(0.86, p=0.05)$. The presence of other microvascular complications, i.e. peripheral neuropathy and retinopathy, was positively related to an adverse outcome (Table 2).

When the risk factors listed above were adjusted for diabetes duration, $\mathrm{HbA}_{1} \mathrm{c}$ and baseline AER, the factors that remained independently related to regression to normoalbuminuria were the WHR and peripheral neuropathy (Table 3 ). In contrast, body weight was the only factor that remained independently related to the risk of progression to macroalbuminuria (Table 3). When standardised regression estimates were compared, AER, WHR and peripheral neuropathy were equally predictive in terms of the risk estimate (Table 4). Once peripheral neuropathy was removed from the model, the esti- 
Table 2. Risk factors at baseline by evolution of microalbuminuria at follow-up

\begin{tabular}{|c|c|c|c|c|}
\hline & \multicolumn{4}{|c|}{ Evolution of microalbuminuria } \\
\hline & $\begin{array}{l}\text { Reverted to } \\
\text { normoalbuminuria } \\
(n=178)\end{array}$ & $\begin{array}{l}\text { Remained } \\
\text { microalbuminuric } \\
(n=125)\end{array}$ & $\begin{array}{l}\text { Progressed to } \\
\text { macroalbuminuria } \\
(n=49)\end{array}$ & $p$ value \\
\hline Age (years) & $32 \pm 10.0$ & $33 \pm 10.3$ & $34 \pm 10.7$ & 0.2 \\
\hline Diabetes duration (years) & $15 \pm 9.2$ & $18 \pm 9.4$ & $18 \pm 10.2$ & 0.004 \\
\hline Diastolic BP (mm Hg) & $77 \pm 11.1$ & $77 \pm 11.9$ & $78 \pm 12.3$ & 0.7 \\
\hline Cholesterol $(\mathrm{mmol} / \mathrm{l})$ & $5.3 \pm 1.0$ & $5.3 \pm 1.1$ & $5.6 \pm 1.2$ & 0.3 \\
\hline Fasting triglyceride $(\mathrm{mmol} / \mathrm{l})^{\mathrm{a}}$ & $0.95(0.87,1.04)$ & $1.02(0.91,1.14)$ & $1.18(0.96,1.44)$ & 0.04 \\
\hline HDL cholesterol (mmol/l) & $1.51 \pm 0.44$ & $1.5 \pm 0.5$ & $1.38 \pm 0.38$ & 0.1 \\
\hline LDL cholesterol (mmol/l) & $3.3 \pm 0.9$ & $3.3 \pm 1.0$ & $3.5 \pm 0.9$ & 0.3 \\
\hline Gamma GT $(\mathrm{U} / \mathrm{ml})^{\mathrm{a}}$ & $10.6(9.6,11.7)$ & $12.0(10.7,13.5)$ & $13.7(11.2,16.8)$ & 0.01 \\
\hline $\operatorname{BMI}\left(\mathrm{kg} / \mathrm{m}^{2}\right)$ & $23.5 \pm 2.7$ & $23.6 \pm 3.0$ & $24.2 \pm 3.1$ & 0.1 \\
\hline WHR & $0.83 \pm 0.1^{\mathrm{c}}$ & $0.86 \pm 0.12$ & $0.86 \pm 0.11$ & 0.05 \\
\hline Insulin/kg body weight (U/kg) ${ }^{\mathrm{a}}$ & $0.65(0.62,0.68)$ & $0.67(0.63,0.71)$ & $0.68(0.63,0.74)$ & 0.3 \\
\hline $\operatorname{AER}(\mu \mathrm{g} / \mathrm{min})^{\mathrm{a}}$ & $37.2(34.1,40.5)$ & $44.9(40.5,49.8)$ & $64.4(53.9,76.8)$ & 0.0001 \\
\hline Peripheral neuropathy (\%) & 24 & 38 & 45 & 0.001 \\
\hline Autonomic neuropathy (\%) & 36 & 39 & 51 & 0.09 \\
\hline Any retinopathy $(\%)$ & 47 & 64 & 67 & 0.002 \\
\hline $\operatorname{CVD}(\%)$ & 7 & 10 & 16 & 0.06 \\
\hline Current smoking (\%) & 32 & 38 & 35 & 0.4 \\
\hline Inject insulin $\geq 2 /$ day $(\%)$ & 53 & 55 & 45 & 0.5 \\
\hline
\end{tabular}

Data are means \pm SD unless otherwise stated. ${ }^{a}$ Geometric mean; ${ }^{b}$ Significantly different from means of normo and micro groups $(p=0.03)$; ${ }^{c}$ Significantly different from means of micro and macro groups $(p=0.03)$. AER, albumin excretion rate; $\mathrm{BP}$, blood pressure; CVD, cardiovascular disease; Gamma GT, gamma-glutamyltransferase; vWF, von Willebrand Factor

Table 3. Baseline risk factors for regression to normoalbuminuria or progression to macroalbuminuria after adjusting for diabetes duration, $\mathrm{HbA}_{1} \mathrm{c}$ and albumin excretion rate

\begin{tabular}{|c|c|c|c|c|}
\hline \multirow[t]{2}{*}{ Risk factor } & \multicolumn{4}{|c|}{ Evolution of microalbuminuria } \\
\hline & $\begin{array}{l}\text { Reverted to } \\
\text { normoalbuminuria }\end{array}$ & $\begin{array}{l}\text { Remained } \\
\text { microalbuminuric }\end{array}$ & $\begin{array}{l}\text { Progressed to } \\
\text { macroalbuminuria }\end{array}$ & $p$ value \\
\hline WHR, mean $(95 \% \mathrm{CI})$ & $0.83(0.82$ to 0.85$)$ & $0.86(0.84$ to 0.88$)$ & & 0.05 \\
\hline Peripheral neuropathy RR (95\% CI) & $0.6(0.3$ to 0.9$)$ & 1 & & 0.03 \\
\hline Weight, $\mathrm{kg}(95 \% \mathrm{CI})$ & & $67(66$ to 70$)$ & $72(69$ to 75$)$ & 0.05 \\
\hline
\end{tabular}

$\mathrm{RR}$, risk ratio

Table 4. Standardised estimates of relative risk (SERR) for regression to normoalbuminuria

\begin{tabular}{llll}
\hline & SERR & 95\% CI & $p$ value \\
\hline Diabetes duration (years) & 0.8 & 0.6 to 1.0 & 0.07 \\
HbA $_{1}$ c & 1.0 & 0.8 to 1.3 & 0.9 \\
AER & 0.7 & 0.6 to 0.9 & 0.009 \\
WHR & 0.8 & 0.6 to 1.0 & 0.08 \\
Peripheral neuropathy & 0.6 & 0.3 to 1.0 & 0.04 \\
\hline
\end{tabular}

SERR was calculated using logistic regression, where all risk factors listed above were included in the model. AER, albumin excretion rate mate for AER was 0.7 (95\% CI: 0.6 to $0.9, p=0.01$ ) and that for WHR was 0.8 (95\% CI: 0.6 to $1.0, p=0.05)$.

For progression to macroalbuminuria, the strongest risk factors were $\mathrm{HbA}_{1} \mathrm{c}$ and $\mathrm{AER}$, followed closely by weight (Table 5). When microalbuminuric patients were divided in quintiles according to baseline $\mathrm{HbA}_{1} \mathrm{c}$, the incidence of subjects progressing to macroalbuminuria increased steadily with increasing levels of $\mathrm{HbA}_{1} \mathrm{c}$, and was four times higher in the highest category of $\mathrm{HbA}_{1} \mathrm{c}$ than in the lowest (Fig. 2).

Hypertension was present in $161(46 \%)$ of the microalbuminuric patients at baseline; however, blood 


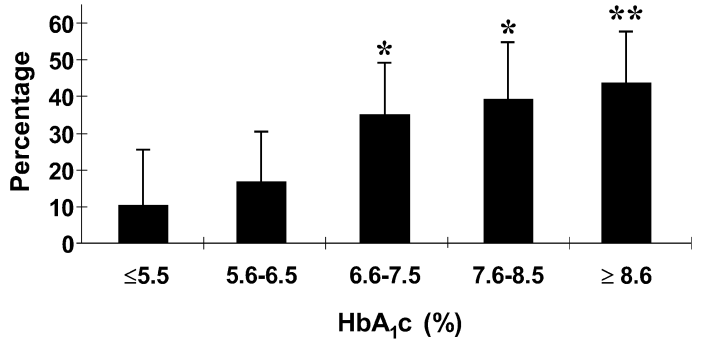

Fig. 2. Relationship between glycaemic control at baseline and percentage of subjects progressing to macroalbuminuria at follow-up. ${ }^{*} p<0.05$ and $* * p<0.01$ vs $\mathrm{HbA}_{1} \mathrm{c} \leq 5.5 \%$

Table 5. Standardised estimates of relative risk (SERR) for progression to macroalbuminuria

\begin{tabular}{llll}
\hline & SERR & $95 \%$ CI & $p$ value \\
\hline Duration & 1.0 & 0.7 to 1.4 & 0.9 \\
HbA $_{1}$ c & 2.1 & 1.4 to 3.0 & 0.0003 \\
AER & 1.9 & 1.3 to 2.8 & 0.0006 \\
Weight & 1.5 & 1.1 to 2.3 & 0.03 \\
\hline
\end{tabular}

SERR was calculated using logistic regression, where all risk factors listed above were included in the model. AER, albumin excretion rate

pressure was not significantly different in microalbuminuric patients who progressed to macroalbuminuria or reverted to normoalbuminuria (Table 2). Only 10\% of the patients were on anti-hypertension medications at the beginning of the study, and when any antihypertensive therapy was taken into account, in the multivariate model the odds ratio (OR) for anti-hypertensive use was $1.19(0.51,1.41)$ for patients who reverted to normoalbuminuria compared to those who remained microalbuminuric $(p=0.5)$, and $0.66(0.23$, $1.89)$ for those who progressed to macroalbuminuria $(p=0.4)$. Therefore, neither baseline blood pressure, nor the use of anti-hypertensive medications emerged as independent risk factors for the outcome of microalbuminuria. When blood pressure distribution was examined at follow-up, $56 \%$ of the patients were found to be hypertensive and 121 (35\% of the total) were on anti-hypertensive medications. Systolic blood pressure at follow-up was significantly higher in those who progressed to macroalbuminuria $(136 \pm 22 \mathrm{~mm}$ $\mathrm{Hg}$ ) than in those who remained microalbuminuric $(125 \pm 21 \mathrm{~mm} \mathrm{Hg})$ or reverted to normoalbuminuria $(120 \pm 18 \mathrm{~mm} \mathrm{Hg})(p<0.01)$, whereas diastolic blood pressure did not differ in the three groups. In addition, a different profile was evident when anti-hypertension therapy was analysed according to AER values at follow-up, because $57 \%$ of patients progressing to macroalbuminuria were on anti-hypertensive medications compared to $42 \%$ of persistently microalbuminuric patients and only $24 \%$ of patients reverting to normoalbuminuria $(p<0.001)$. Approximately $83 \%$ of those on anti-hypertensive therapy at follow-up were using ACE-inhibitors, and this proportion did not differ in those who had regressed to normal AER values $(83 \%)$, in those who had remained microalbuminuric $(81 \%)$, or in those who had progressed to macroalbuminuria $(88 \%)(p=0.8)$.

\section{Discussion}

The EURODIAB PCS is a Europe-wide cohort study of subjects with Type 1 diabetes. Its aim is to examine risk factors associated with the incidence and progression of complications. In this study, we have evaluated the baseline determinants of progression to macroalbuminuria (AER $>200 \mu \mathrm{g} / \mathrm{min}$ ) and of regression to normoalbuminuria (AER $<20 \mu \mathrm{g} / \mathrm{min}$ ) in a population of 352 Type 1 diabetic patients who were microalbuminuric at baseline. After a median follow-up period of 7 years, about $14 \%$ progressed to macroalbuminuria (two per 100 person-years), 51\% were found to be normoalbuminuric and $35 \%$ remained microalbuminuric. Examination of the relationship between risk factors at baseline and evolution of microalbuminuria showed that levels of $\mathrm{HbA}_{1} \mathrm{c}, \mathrm{AER}$ and body weight at baseline were associated with the progression to macroalbuminuria (Tables 2, 3). Conversely, diabetes duration, AER, WHR and incidence of peripheral neuropathy were lowest at baseline in patients who reverted to normoalbuminuria (Tables 2, 3).

These observations confirm that microalbuminuria is a very good predictor of the risk of developing diabetic kidney disease in Type 1 diabetes. Furthermore, detection of microalbuminuria in the higher range identifies those patients with a particularly high risk of clinical nephropathy. In fact, the rate of progression from microalbuminuria to clinical albuminuria and the significance of microalbuminuria as a predictor of diabetic nephropathy have been a matter of debate [12, 13]. Early retrospective studies described a risk of progression from microalbuminuria to macroalbuminuria of approximately $80 \%$ in 6 to 14 years (i.e. six to ten per 100 person-years) $[14,15,16]$. However, in subsequent observational and intervention studies, the observed rate of progression was shown to vary considerably between 2.8 [17] and 13 [18] per 100 person-years. Potential explanations of the observed disparities in the various studies lie in the non-homogeneous diagnostic criteria for micro- and macroalbuminuria and differences in critical determinants of microalbuminuria, including diabetes duration, blood pressure, anti-hypertensive therapy and metabolic control.

Multiple factors may account for the apparently low incidence of macroalbuminuria observed in our study (two per 100 person-years). Firstly, median diabetes duration at baseline was 16 years, a time frame during which a significant amount of Type 1 patients may have already progressed to clinical nephropathy, 
and according to older epidemiological studies [19, 20], persistently microalbuminuric patients may be at relatively low risk of progressing to that condition. However, in a recent study [21], the rate of progression to macroalbuminuria in patients with diabetes duration in excess of 30 years was 4.5 per 100 person-years, supporting the notion that even Type 1 diabetic patients with long disease duration may show a significant rate of progression to overt nephropathy. Secondly, a valid AER estimation was obtained in $63.5 \%$ of potentially available patients (352/554). Although prospective studies carried out in single centres have a higher follow-up rate $[22,23]$, the proportion of patients completing the follow-up tends to decrease with time when large groups of patients are recruited [24], and this is particularly true given the broad European scope of the EURODIAB multicentre study. Patients not available at follow-up had worse metabolic control, as indicated by higher $\mathrm{HbA}_{1} \mathrm{c}$ and triglyceride concentrations. However, mean AER values and the distribution of AER values at baseline were no different in this group than in patients available at follow-up (Table 1).

As expected, glycaemic control was also strongly associated with progression to macroalbuminuria, in line with multiple follow-up studies [25, 26, 27]. However, some intervention studies found no significant effect of improved glycaemic control on the risk of progression to overt proteinuria [28, 29]. In those trials it is possible that genetic heterogeneity in alleles associated with development of and/or progression to diabetic nephropathy [30] or an inadequate sample size may have masked a favourable impact of intensive control of hyperglycaemia on the evolution of nephropathy. Recently, Warram et al. [31] studied a large cohort of approximately 300 microalbuminuric Type 1 diabetic subjects for 4 years, and found an increasing risk of developing overt proteinuria for patients with baseline $\mathrm{HbA}_{1} \mathrm{c}$ up to $8.5 \%$. Similarly, when patients of the EURODIAB cohort were divided into quintiles according to baseline $\mathrm{HbA}_{1} \mathrm{c}$, risk of progression to clinical albuminuria increased steeply, from approximately 1.5 per 100 person-years in the lowest $\mathrm{HbA}_{1} \mathrm{c}$ category to 6.2 per 100 person-years in the highest (Fig. 2). However, $\mathrm{HbA}_{1} \mathrm{c}$ did not emerge as an independent factor associated with regression to normoalbuminuria (Table 4). It is not clear whether this suggests a threshold effect or simply the lack of statistical power due to the relatively good metabolic control in these patients $\left(\mathrm{HbA}_{1} \mathrm{c}<7.0 \%\right)$. Overall, our data support the notion that worse metabolic control, as indicated by higher $\mathrm{HbA}_{1} \mathrm{c}$ levels, can identify those patients with greater risk of progression to macroalbuminuria.

After adjusting for diabetes duration, $\mathrm{HbA}_{1} \mathrm{c}$ and AER, body weight remained independently related to the development of macroalbuminuria. Conversely, Type 1 diabetic patients with microalbuminuria and lowest WHR had a greater tendency to revert to normoalbuminuria, suggesting that a lower level of abdominal fat accumulation may be a protective factor for the development of kidney damage. In the EURODIAB cohort, Type 1 diabetic patients with higher WHR were found to carry a greater risk of developing microalbuminuria [3] and retinopathy [32] than those patients with lower abdominal fat. In another study, body weight reduction following caloric restriction was associated with a marked reduction of albuminuria and improvement of kidney function in obese Type 1 and Type 2 diabetic patients [33].

Insulin resistance is a feature of Type 1 diabetic patients with microalbuminuria, and this contributes to the increased risk of cardiovascular disease in these patients $[34,35]$. Notably, in the univariate analysis of this study, both fasting triglyceride and vWF plasma levels, both of which are associated with the insulin resistance syndrome, were significantly higher in patients progressing to overt albuminuria. On the other hand, microalbuminuria may represent a marker of extensive endothelial dysfunction (or generalised vascular damage), which can be the cause both of insulin resistance and of nephropathy. Since abdominal fat accumulation is a phenotypic hallmark of insulin resistance, Type 1 diabetic patients with increased abdominal fat may be particularly prone to vascular impairment, leading to a greater degree of progression to nephropathy (this study) and retinopathy [32].

Approximately $50 \%$ of the 352 Type 1 diabetic subjects who were microalbuminuric at baseline were found to be normoalbuminuric at follow-up. The estimation of patients regressing to normal AER values in our study might have some limitations. The study was originally designed with only one urine collection at baseline, and this could be a potential cause of misclassification of patients, especially for patients with AER values close to the lower limit. However, one potential source of false positives was excluded by testing urine samples for infection. In addition, all manipulations of biological samples were performed locally using a centrally standardised protocol, and AER was measured in a single central laboratory, which was the same for baseline and follow-up urine analyses. It should be noted that the coefficient of reliability, calculated at baseline on a subset of patients with duplicate urine collections, was found to be very high (0.97) [2]. Under these conditions, any potential misclassification of normoalbuminuric patients as microalbuminuric would not affect the identification of risk factors for progression to clinical nephropathy. In this study, more than $60 \%$ of patients found to be normoalbuminuric at follow-up had baseline AER values close to the lower limit (20-40 $\mu \mathrm{g} / \mathrm{min})$. In earlier observational studies, the percentage of microalbuminuric patients reverting to normal AER ranged from $7 \%$ [16] to 58\% [36] of enrolled patients. In a recent 6-year follow-up analysis of Type 1 diabetic patients with AER levels between 30 and $299 \mu \mathrm{g} / \mathrm{min}$ at base- 
line, regression of microalbuminuria was defined both as an absolute AER value of less than $30 \mu \mathrm{g} / \mathrm{min}$, and as a $50 \%$ reduction of AER. This was done to make the estimate independent of the AER lower threshold [24]. Both assessments gave a similar cumulative proportion of patients reverting to normoalbuminuria (59\% and 58\% respectively, for the 6-year interval), which is similar to the proportion found in this study (50.6\% in 7 years).

We were unable to detect any predictive value of baseline blood pressure, systolic or diastolic, on the evolution of microalbuminuria. This may seem surprising in light of the clear positive effect of blood pressure control on the evolution of diabetic nephropathy in most intervention studies (for review, see [37]). However, the aim of this study was to identify potential baseline factors associated with risk of progression of microalbuminuria to macroalbuminuria, rather than to evaluate the effects of control of blood pressure or other clinical parameters on the evolution of microalbuminuria. Indeed, blood pressure was found to be a risk marker for incidence of microalbuminuria and progression to overt nephropathy in some $[22,31]$, but not all observational studies, including the EURODIAB PCS in a previous analysis of 1134 normoalbuminuric patients $[3,21,23,38]$. It is possible that the increase in blood pressure in patients progressing to overt nephropathy is evident only in close temporal relationship with the increase in AER, and thus may have been missed in the 7-year follow-up interval. It has also been observed that an increase in AER values in Type 1 diabetic subjects may be heralded by an abnormal pattern of night-time blood pressure [39]. We cannot, therefore, rule out that differences in blood pressure at baseline may not have been detectable with a single office measurement, but could have been found if 24-h blood pressure measurements had been performed [40, 41]. However, at follow-up, systolic blood pressure and the use of anti-hypertension medications were higher in patients who had progressed to macroalbuminuria.

In this study, smoking was not associated with progression of diabetic nephropathy. A similar finding has been reported in previous cross-sectional or prospective studies [22, 42], but not in all studies [43, 44]. The prevalence of ex-smokers in the total EURODIAB cohort was about $23 \%$ in men and $14 \%$ in women. Even though ex-smokers had significantly higher AER values than patients who never smoked, the prevalence of microalbuminuria did not differ in these two subgroups [44].

In conclusion, the results of this study confirm that a significant fraction of Type 1 diabetic patients with microalbuminuria will progress to overt proteinuria. Patients with higher AER values, suboptimal metabolic control and excess body fat may carry a particularly high risk of clinical nephropathy and require prompt therapeutic intervention.
Acknowledgements. The EURODIAB PCS was supported by project grants from the Wellcome Trust, the European Community and Diabetes UK. We would like to thank all staff and patients who took part in the study.

\section{The EURODIAB Prospective Complications Study Group:}

B. Karamanos, A. Kofinis, K. Petrou, Hippokration Hospital, Athens, Greece

F. Giorgino, G. Picca, A. Angarano, G. De Pergola, L. Laviola, R. Giorgino, Internal Medicine, Endocrinology and Metabolic Diseases, Department of Emergency and Organ Transplantation, University of Bari, Italy

C. Ionescu-Tirgoviste, A. Coszma, C. Guja, Clinic of Diabetes, Nutrition \& Metabolic Diseases, Bucharest, Romania

M. Songini, A. Casu, M. Pedron, S. Pintus, M. Fossarello*, Diabetes Unit and Ophthalmology Dept*, Ospedale San Michele, Cagliari, Italy

J. B. Ferriss, G. Grealy, D. O. Keefe, Cork University Hospital, Ireland

M. Toeller, C. Arden, Diabetes Research Institute, HeinrichHeine University, Düsseldorf, Germany

R. Rottiers, C .Tuyttens, H. Priem, University Hospital of Gent, Belgium

P. Ebeling, M. Kylliäinen, V. A. Koivisto, University Hospital of Helsinki, Finland

B. Idzior-Walus, J. Sieradzki, K. Cyganek, B. Solnica, Department of Metabolic Diseases, Jagiellonian University, Krakow, Poland

H. H. P. J. Lemkes, J. C. Lemkes-Stuffken, Leiden University Medical Centre, the Netherlands

J. Nunes-Correa, M. C. Rogado, L. Gardete-Correia, M. C. Cardoso, A. Silva, J .Boavida, M. Machado Sa Marques, Portuguese Diabetic Association, Lisbon, Portugal

G. Michel, R. Wirion, S. Cardillo, Centre Hospitalier, Luxembourg

G. Pozza, R. Mangili, V. Asnaghi, Ospedale San Raffaele, Milan, Italy

E. Standl, B. Schaffler, H. Brand, A. Harms, City Hospital Schwabing, Munich, Germany

D. Ben Soussan, O. Verier-Mine, P. Fallas, M. C. Fallas, Centre Hospitalier de Valenciennes, France

J. H. Fuller, J. Holloway, L. Asbury, D. J. Betteridge, University College, London, UK

G. Cathelineau, A. Bouallouche, B. Villatte Cathelineau, Hospital Saint-Louis, Paris, France

F. Santeusanio, G. Rosi, V. D’Alessandro, C. Cagini, P. Bottini, G. P. Reboldi, Department of Internal Medicine, Perugia, Italy

R. Navalesi, G. Penno, S. Bandinelli, R. Miccoli, M. Nannipieri, Department of Endocrinology and Metabolism, Pisa, Italy

G. Ghirlanda, C. Saponara, P. Cotroneo, A. Manto, A. Minnella, Università Cattolica del Sacro Cuore, Rome, Italy

J. D. Ward, S. Tesfaye, S. Eaton, C. Mody, Royal Hallamshire Hospital, Sheffield, UK

M. Borra, P. Cavallo Perin, S. Giunti, G. Grassi, G. F. Pagano, M. Porta, R. Sivieri, F. Vitelli, D. Ferrari, Department of Internal Medicine, University of Turin and ASO CTO/ CRF/Maria Adelaide, Turin, Italy

N. Papazoglou, G. Manes, General Hospital of Thessaloniki, Greece

M. Muggeo, M. Iagulli, V. Cacciatori, Cattedra di Malattie del Metabolismo, Verona, Italy

K. Irsigler, H. Abrahamian, Hospital Vienna Lainz, Austria

S. Walford, J. Sinclair, S. Hughes, V. McLelland, J. Ward, New Cross Hospital, Wolverhampton, UK 
G. Roglic, Z. Metelko, Z. R. Pepeonik, Z. Babic, Vuk Vrhovac Institute for Diabetes, Zagreb, Croatia Steering committee members: J. H. Fuller (London), B. Karamanos, Chairman (Athens), A.-K. Sjolie (Aarhus), N. Chaturvedi (London), M. Toeller (Düsseldorf), G. Pozza, Co-Chairman (Milan), B. Ferriss (Cork), M. Porta (Turin),

R. Rottiers (Gent), G. Michel (Luxembourg)

Co-ordinating centre: J. H. Fuller, N. Chaturvedi, J. Holloway,

D. Webb, L. Asbury, University College London, UK

Central laboratories: G.-C. Viberti, R. Swaminathan, P.

Lumb, A. Collins, S. Sankaralingham, Guy's and St Thomas

Hospital, London, UK

Retinopathy grading centre: S. Aldington, T. Mortemore, H. Lipinski, Royal Postgraduate Medical School of Imperial College London, UK

\section{References}

1. American Diabetes Association (2003) Diabetic Nephropathy. Diabetes Care 26:S94-S98

2. The EURODIAB IDDM Complications Study Group (1994) Microvascular and acute complications in IDDM patients: the EURODIAB IDDM Complications Study. Diabetologia 37:278-285

3. Chaturvedi N, Bandinelli S, Mangili R, Penno G, Rottiers RE, Fuller JH (2001) Microalbuminuria in Type 1 diabetes: rates, risk factors and glycemic threshold. Kidney Int 60:219-227

4. Kearney EM, Mount JN, Watts GF, Slavin BM, Kind PR (1987) Simple immunoturbidimetric method for determining urinary albumin at low concentrations using Cobas-Bio centrifugal analyser. J Clin Pathol 40:465-468

5. Tesfaye S, Stevens LK, Stephenson JM et al. (1996) Prevalence of diabetic peripheral neuropathy and its relation to glycaemic control and potential risk factors: the EURODIAB IDDM Complications Study. Diabetologia 39:1377-1384

6. Siedel J, Hagele EO, Ziegenhorn J, Wahlefeld AW (1983) Reagent for the enzymatic determination of serum total cholesterol with improved lipolytic efficiency. Clin Chem 29:1075-1080

7. Bucolo G, David H (1973) Quantitative determination of serum triglycerides by the use of enzymes. Clin Chem 19:476-482

8. Warnick GR, Albers JJ (1978) A comprehensive evaluation of the heparin-manganese precipitation procedure for estimating high density lipoprotein cholesterol. J Lipid Res 19:65-76

9. Friedewald WT, Levy RI, Fredrickson DS (1972) Estimation of the concentration of low-density lipoprotein cholesterol in plasma, without use of the preparative ultracentrifuge. Clin Chem 18:499-502

10. John WG, Gray MR, Bates DL, Beacham JL (1993) Enzyme immunoassay-a new technique for estimating hemoglobin A1c. Clin Chem 39:663-666

11. Ford I, Malik RA, Newrick PG, Preston FE, Ward JD, Greaves M (1992) Relationships between haemostatic factors and capillary morphology in human diabetic neuropathy. Thromb Haemost 68:628-633

12. Caramori ML, Fioretto P, Mauer M (2000) The need for early predictors of diabetic nephropathy risk: is albumin excretion rate sufficient? Diabetes 49:1399-1408

13. Parving $\mathrm{HH}$, Chaturvedi N, Viberti G, Mogensen $\mathrm{CE}$ (2002) Does microalbuminuria predict diabetic nephropathy? Diabetes Care 25:406-407
14. Parving HH, Oxenboll B, Svendsen PA, Christiansen JS, Andersen AR (1982) Early detection of patients at risk of developing diabetic nephropathy. A longitudinal study of urinary albumin excretion. Acta Endocrinol (Copenh) 100:550-555

15. Viberti GC, Hill RD, Jarrett RJ, Argyropoulos A, Mahmud U, Keen H (1982) Microalbuminuria as a predictor of clinical nephropathy in insulin-dependent diabetes mellitus. Lancet 1:1430-1432

16. Mogensen CE, Christensen CK (1984) Predicting diabetic nephropathy in insulin-dependent patients. N Engl J Med 311:89-93

17. Forsblom CM, Groop PH, Ekstrand A, Groop LC (1992) Predictive value of microalbuminuria in patients with insulin-dependent diabetes of long duration. BMJ 305:10511053

18. Viberti G, Mogensen CE, Groop LC, Pauls JF (1994) Effect of captopril on progression to clinical proteinuria in patients with insulin-dependent diabetes mellitus and microalbuminuria. European Microalbuminuria Captopril Study Group. JAMA 271:275-279

19. Andersen AR, Christiansen JS, Andersen JK, Kreiner S, Deckert T (1983) Diabetic nephropathy in Type 1 (insulindependent) diabetes: an epidemiological study. Diabetologia 25:496-501

20. Bojestig M, Arnqvist HJ, Hermansson G, Karlberg BE, Ludvigsson J (1994) Declining incidence of nephropathy in insulin-dependent diabetes mellitus. $N$ Engl J Med 330:15-18

21. Arun CS, Stoddart J, Mackin P, MacLeod JM, New JP, Marshall SM (2003) Significance of microalbuminuria in long-duration type 1 diabetes. Diabetes Care 26:2144-2149

22. The Microalbuminuria Collaborative Study Group (1999) Predictors of the development of microalbuminuria in patients with Type 1 diabetes mellitus: a seven-year prospective study. Diabet Med 16:918-925

23. Rossing P, Hougaard P, Parving HH (2002) Risk factors for development of incipient and overt diabetic nephropathy in type 1 diabetic patients: a 10-year prospective observational study. Diabetes Care 25:859-864

24. Perkins BA, Ficociello LH, Silva KH, Finkelstein DM, Warram JH, Krolewski AS (2003) Regression of microalbuminuria in Type 1 diabetes. N Engl J Med 348:22852293

25. Almdal T, Norgaard K, Feldt-Rasmussen B, Deckert T (1994) The predictive value of microalbuminuria in IDDM. A five-year follow-up study. Diabetes Care 17:120-125

26. Rudberg S, Dahlquist G (1996) Determinants of progression of microalbuminuria in adolescents with IDDM. Diabetes Care 19:369-371

27. The Microalbuminuria Captopril Study Group (1996) Captopril reduces the risk of nephropathy in IDDM patients with microalbuminuria. Diabetologia 39:587-593

28. Microalbuminuria Collaborative Study Group, United Kingdom (1995) Intensive therapy and progression to clinical albuminuria in patients with insulin dependent diabetes mellitus and microalbuminuria. BMJ 311:973-977

29. The Diabetes Control and Complications (DCCT) Research Group (1995) Effect of intensive therapy on the development and progression of diabetic nephropathy in the Diabetes Control and Complications Trial. Kidney Int 47:1703-1720

30. Orisio S (1999) Gene polymorphism of the renin-angiotensin system and progression of diabetic nephropathy. J Nephrol 12:9-17

31. Warram JH, Scott LJ, Hanna LS et al. (2000) Progression of microalbuminuria to proteinuria in Type 1 diabetes: nonlinear relationship with hyperglycemia. Diabetes 49:94-100 
32. Chaturvedi N, Sjoelie AK, Porta M et al. (2001) The EURODIAB Prospective Complications Study. Markers of insulin resistance are strong risk factors for retinopathy incidence in Type 1 diabetes. Diabetes Care 24:284-289

33. Solerte SB, Fioravanti M, Schifino N, Ferrari E (1989) Effects of diet-therapy on urinary protein excretion albuminuria and renal haemodynamic function in obese diabetic patients with overt nephropathy. Int J Obes 13:203-211

34. Yip J, Mattock MB, Morocutti A, Sethi M, Trevisan R, Viberti G (1993) Insulin resistance in insulin-dependent diabetic patients with microalbuminuria. Lancet 342:883887

35. De Cosmo S, Bacci S, Piras GP et al. (1997) High prevalence of risk factors for cardiovascular disease in parents of IDDM patients with albuminuria. Diabetologia 40:11911196

36. Bojestig M, Arnqvist HJ, Karlberg BE, Ludvigsson J (1996) Glycemic control and prognosis in Type I diabetic patients with microalbuminuria. Diabetes Care 19:313-317

37. Mogensen CE (2003) Microalbuminuria and hypertension with focus on type 1 and type 2 diabetes. J Intern Med 254:45-66

38. Mathiesen ER, Ronn B, Storm B, Foght H, Deckert T (1995) The natural course of microalbuminuria in insulin- dependent diabetes: a 10-year prospective study. Diabet Med 12:482-487

39. Lurbe E, Redon J, Kesani A et al. (2002) Increase in nocturnal blood pressure and progression to microalbuminuria in type 1 diabetes. N Engl J Med 347:797-805

40. Poulsen PL, Hansen KW, Mogensen CE (1994) Ambulatory blood pressure in the transition from normo- to microalbuminuria. A longitudinal study in IDDM patients. Diabetes 43:1248-1253

41. Voros P, Lengyel Z, Nagy V, Nemeth C, Rosivall L, Kammerer L (1998) Diurnal blood pressure variation and albuminuria in normotensive patients with insulin-dependent diabetes mellitus. Nephrol Dial Transplant 13:22572260

42. Hovind P, Rossing P, Tarnow L, Parving HH (2003) Smoking and progression of diabetic nephropathy in Type 1 diabetes. Diabetes Care 26:911-916

43. Christiansen JS (1978) Cigarette smoking and prevalence of microangiopathy in juvenile-onset insulin-dependent diabetes mellitus. Diabetes Care 1:146-149

44. Chaturvedi N, Stephenson JM, Fuller JH (1995) The relationship between smoking and microvascular complications in the EURODIAB IDDM Complications Study. Diabetes Care 18:785-792 